Article

\title{
Analyzing Financial Health of the SMES Listed in the AERO Market of Bucharest Stock Exchange Using Principal Component Analysis
}

\author{
Claudia Diana Sabău-Popa ${ }^{1, *(\mathbb{D})}$, Ramona Simut ${ }^{2}{ }^{\mathbb{D}}$, Laurențiu Droj ${ }^{1}$ \\ and Corneliu Cristian Bențe ${ }^{1}$ \\ 1 Department of Finance-Accounting, Faculty of Economic Sciences, University of Oradea, \\ 410087 Oradea, Romania; ldroj@uoradea.ro (L.D.); cbente@uoradea.ro (C.C.B.) \\ 2 Department of Economics and Business, Faculty of Economic Sciences, University of Oradea, \\ 410087 Oradea, Romania; simut.ramona@yahoo.com \\ * Correspondence: dpopa@uoradea.ro; Tel.: +40-741-206-643
}

Received: 22 March 2020; Accepted: 1 May 2020; Published: 4 May 2020

\begin{abstract}
In this paper we aimed to build a composite financial index for measuring the financial health of the companies listed in the AERO (Alternative exchange in Romania) market of the Bucharest Stock Exchange. We used a principal component analysis in order to build this composite financial index using the rates of return, liquidity and the management of 25 companies listed in the AERO market for the period 2011-2018. We conceived this composite indicator as a score function that established according to the numerical values that result from its application when a company was financially healthy, when it had a poor financial health and when it was financially stable. In order to test the financial health of the selected SMEs (small and medium enterprises), we used the one sample $t$-test under the model of the study and the three classifications of $Z(Z<0-$ companies with poor financial health, $0 \leq Z \leq 0.5$-companies with good financial health and $Z>0.5$-companies with very good financial health). In this study we also aimed to identify the possible correlations between the solvency rate and the financial health index and between solvency rate and the evolution of some economic and financial measures of the companies' activities. The results of the regression analysis using panel data showed a positive and statistically significant relation between solvency and the three rates (rates of return, of liquidity and of management, respectively) determined using the analysis of the principal components. The former model of the solvency rate identified correctly $94.9 \%$ of the SMEs with poor financial health, $40 \%$ of the SMEs with stable financial health and $72.2 \%$ of the SMEs with good financial health.
\end{abstract}

Keywords: financial indicators; composite index; PCA; financial sustainability; small and medium-sized companies; financial health; AERO market

JEL Classification: C43; G39; M21; C33

\section{Introduction}

The financial sustainability of small and medium-sized companies has a direct and significant influence on the development and growth of the economy where they are located. This is extremely important in the EU, since the European economies are characterized by the overwhelming predominance of small and medium-sized companies. In Romania, the share of small and medium-sized enterprises is $99.7 \%$ of the total companies in the non-financial sector, generating $53.2 \%$ of the total added value and having almost $65.8 \%$ of the total employees in the non-financial business sector of the country [1]. 
The measure of the financial sustainability of the companies is given by the indicators of performance, liquidity, management and indebtedness, in fact indicating the financial health of the companies.

Zabolotnyy S. and Wasilewski M. [2] defined financial sustainability as the ability of the company to generate profit and to increase the value of the invested capital by its shareholders, as well as to operate continuously through the optimal use of financial sources in order to assure the long-term financial equilibrium.

The financial health of a company is an economic and financial state which is found using modern and high-performance equipment and advertising in promoting its goods and services, ensuring its profit maximization [3].

We can say with certainty that financial sustainability is the main pillar of the economic sustainability of companies that reflects the efficient use of the company assets so as to generate profit. The measure of financial sustainability is given mostly by the degree of the financial health of the companies, which can be diagnosed using several financial indicators such as liquidity, performance, debt and management indicators. The liquidity indicators used in this paper are the current liquidity rate and the immediate liquidity rate, which show the ability of companies to pay off their short-term debts from the assets held, respectively from the available cash. The selected financial performance indicators are: return on assets (ROA) and return on equity (ROE). Return on equity shows the return of investments made by the shareholders by purchasing shares of the company. The return on assets shows the total asset performance and the overall efficiency of the company's management to generate profits using the assets [4].

The management rates are particularly important because they show us the efficiency of a company in using its own assets, the most relevant for our purpose of analysis being the duration of the stock rotation, the receivables' duration and the payment duration of the suppliers. If we have a negative difference between the duration of the receivables and the payment time of the suppliers, this aspect reflects a short-term cash deficit and possible liquidity problems of the company in discussion.

At the same time, for diagnosing the financial health of the companies we considered the general solvency rate, which shows the degree to which the total debts of the company are covered by the assets held by it, as well as the rate of the financial leverage, which expresses the total debt of the company in relation to its own capital.

In the following lines we will diagnose the financial health of the companies, building a composite financial index based on the main rates of liquidity, management and return and using a principal component analysis.

\section{Literature Review}

Over time, several studies and algorithms have been developed to test the financial health of companies and to measure their financial sustainability.

In their work [5], Nyabwanga, R. N., Ojera, P., O. Simeyo and Nyakundi F realized a financial diagnosis of the small and medium enterprises' (SMEs) financial performance using statistical analysis and Altman's Z-score model. Their study focused on small and medium-sized companies in the Kisii Municipality, Kenya, showing that the liquidity and solvency of the analyzed companies was low, highlighting a significant influence of the current rate, rapid liquidity rate and the overall solvency on the return on the assets.

Maciková L., Smorada M., Dorčák P., Beug B. and Markovič P. [6] have developed an integral indicator of business sustainability and linked it to the economic value added, using a financial ratios method and the correlation and linear regression analysis methods. Their research results showed a strong direct dependence of the financial performance on the integral business sustainability indicator for the three sectors of activity analyzed by the authors. 
Zabolotnyy S. and M. Wasilewski M. [2] have designed a measurement indicator of financial sustainability. They used the fuzzy logic method to quantify complex interrelations among various financial factors and divided the companies according to their financial sustainability level.

Salawu [7] presented an analysis of the relationship between the capital structure and the profitability of companies listed in the Nigerian Stock Exchange for the period 1990-2004, using panel data econometric techniques. The results of the study can be summarized as: the impact of the capital structure was not significant, but there was a positive relationship between the profitability and short-term debts and an inverse correlation with long-term debt. A higher proportion of the short-term debt in total debt makes the corporate sector from Nigeria extremely vulnerable to the changes occurring in the economic environment.

In their article [8], Lassala C., Apetrei A. and Sapena J. used the fuzzy-set qualitative comparative analysis to analyze the relationship between both types of performance in a sample of the companies listed in the Spanish capital market. The results obtained by the authors showed that the ROA ratio was a necessary condition for achieving the optimal level of the ROE ratio, and also that corporate social performance affected financial performance by facilitating firms with efficient operations with access to financing at a low cost.

Kočišováa K. and Mišanková M. [9] have shown how the multiple discriminant analysis technique can be used to predict the financial health of companies and to send alarm signals to the management of companies. The authors presented the advantages and disadvantages of using the multiple discriminant analysis technique for predicting the financial health of companies compared to other prediction techniques. Hur-Yagba A. A., Fari Okeji I. and Ayuba B. [10] also conducted a comparative study between two large Nigerian companies, analyzing the correlation between liquidity, profitability, debt ratios and the solvency or insolvency of manufacturing companies. The authors used Altman's multiple discriminate analysis model and the results of the study showed that this model was useful in predicting bankruptcy.

An analysis of the financial sustainability of the main Romanian companies operating in the energy sector was made by Păun D. [11]. The author conducted a horizontal analysis to identify the trend in the energy sector and calculated the return on assets, the return on equity and the overall solvency rate to measure the financial performance and sustainability of the companies. The results of the study showed that the financial sustainability of the companies operating in the renewable energy sector was doubtful as being significantly related to government subsidies.

Sannikova N. and Prikhodko E. A. [3] used an analysis of time series to assess the dynamics of financial indicators of Russian companies according to their financial statements and developed a methodology for assessing the financial health of a company and an integral indicator of "financial health" (IFHI) based on the main performance indicators, indebtedness and the managements rates of the companies.

An analysis of the reliability of the models for predicting the financial health of the companies financed by European funds has been carried out by the authors Čámská D. and Scholleová H. [12]. The prediction models analyzed were on the one hand the models used by Czech financial support programs and on the other hand the Altman prediction model, the results of this study being in favor of the specific models of financial support programs from the Czech Republic.

\section{Data Collection}

The method of clustered sampling is a probability sampling technique in which all population elements are categorized into mutually exclusive and exhaustive groups called clusters [13]. In order to apply the sampling plan, the population is divided into these groups (clusters) and then a simple random sample of the groups is selected [14]. In this paper we used two stage cluster samples. The test subjects were first divided based on their field of activity and afterwards the elements in each cluster were further sampled based on financial criteria. In this article we aimed to analyze the financial health of 25 small and medium-sized companies listed in the AERO (Alternative exchange in Romania) market 
of the Bucharest Stock Exchange. The sectors of activity in which the selected companies operated were the construction sector, the hotel, restaurant and catering sector (HORECA) and the processing industry sector. These sectors have a significant contribution to the formation of Romania's GDP. The data used were annual, the studied period was between 2011 and 2018 and the data was collected from the annual financial statements of the selected companies listed in the Bucharest Stock Exchange site [15], the AERO market. In the AERO market of the Bucharest Stock Exchange were listed small and medium-sized companies which cumulatively fulfilled the three following criteria [15]: they were joint stock companies, they had an early capitalization/equity of at least 250,000 euros, and they had a free float of $10 \%$.

In order to highlight the financial health and sustainability of these 25 Romanian companies, we intended to develop a scoring function taking into account seven financial and economic indicators for the activity of the companies. The variables used in the analysis are presented in Table 1.

Table 1. Variables description.

\begin{tabular}{ccc}
\hline Abbreviation & Computing Formula & Variable \\
\hline ROA & (Net income/Total assets) $\times 100$ & Return on asset \\
ROE & Net income/Equity & Return on equity \\
RLC & Working capital/Short-term debt & Current liquidity rate \\
RLI & Money availability/Short-term debt & Quick liquidity rate \\
DRS & Stock $\times 365 /$ Net turnover & Average duration of stock rotation \\
DRC & Receivables $\times 365 /$ Net turnover & Average duration of short-term \\
& receivables rotation \\
DRF & Short-term debt to current suppliers $\times 365 /$ Net turnover & Average rotation time \\
RSG & Total assets/(Long-term debt + short-term debt) & Solvent suppliers \\
L & (Short-term debt + long-term debt $/$ Equity & Financial leverage \\
\hline
\end{tabular}

The return on equity (ROE) showed the net income returned as a percentage of the shareholders' equity. The desirable level of this rate is higher than the average interest rate on the banking market, in order to make the company's shares more attractive to potential investors.

The return on assets (ROA) showed how effective firm management was using its assets to generate income [16]. This rate must be higher than the inflation rate and the average interest rate on the banking market, to ensure the remuneration of the invested capital at a level which is higher than the average interest rate.

The current liquidity rate (RLC) reflects the ability of the company to pay its short-term debts from the current assets held. The quick liquidity rate (RLI) showed the ability of the company to pay its short-term debts from its most liquid assets. The higher the value of the liquidity rates, the more the company has the ability to pay its current debts from its current assets (in the case of RLC) or from its most liquid assets (in the case of RLI), without resorting to long-term sources. A subunit value of the liquidity rates shows that the company is financing part of the fixed assets by short-term debt, which increases the risk of bankruptcy.

The management rates (DRC, DRS, DRF) expressed the intensity of the exploitation of the company's assets. The more intense they are exploited, the lower the speed of the rotation is. The average duration of stock rotation (DRS) reflected the average number of days required for stock renewal. This indicator varies greatly depending on the specific activity and the sector in which the company operates and takes into account all types of stocks. The average rotation time of the current suppliers (DRF) expressed the average number of days in which the payment obligations to the company's current suppliers were fulfilled. A high and increasing value of DRF can be a signal for non-payment of the suppliers and can lead to the insolvency of the respective company. The average duration of short-term receivables rotation (DRC) reflected the average number of days in which the company collected its short-term receivables. A small value of this indicator shows an efficient commercial policy. If the average rotation time of the current suppliers (DRF) 
is smaller than the average duration of the short-term receivables rotation (DRC), this could reflect an unfavorable situation for the company, i.e., it pays its suppliers in a shorter period of time than it receives the money from customers, which could lead to a short-term cash deficit.

Financial leverage expressed the total indebtedness of the company in relation to its equity. An increase of the financial leverage rate may lead to an increase in the expected financial rate of return, but it also increases the risk of the company [4]. The solvency rate highlighted the ability of a company to meet its long- and medium-term debts from the assets it holds. Based on this indicator one can evaluate the risk of insolvency or risk of bankruptcy. A higher financial health is obtained if the values of this indicator are reaching higher over par values.

\section{Financial Health Composite Index Design Using Principal Component Analysis (PCA)}

The variables come in a variety of statistical units, these having different intervals or scales. Thus, in order to be able to process them, these variables must be put together on a common basis in order to avoid the problems of mixing the units of measurement. Moreover, a quite important problem in the construction of composite indices is the lack of data. In this study, the multiple imputation technique was implemented. Given the large difference between the units of measurement and the range of values of the seven indicators that we used in constructing a financial health index, it was necessary to standardize the data. Standardization is the most common method used to normalize variables, which has desirable characteristics when it comes to aggregation. By this method, all the variables were converted to a common scale that assumed a "normal" distribution; the more it has an average equal to zero, the more it means that it avoids introducing the aggregation distortions that result from the differences of the variable means $[17,18]$. The formula is:

$$
z_{i j}=\frac{x_{i j}-\overline{x_{j}}}{\sigma}
$$

where: $z_{i j}$ represents the standardized date; $x_{i j}$ represents the $j$-th original variable value of the $i$-th sample; $\overline{x_{j}}$ represents the average value of $x_{j} ; \sigma$ represents the standard deviation. Thus, positive values for a given company indicate an above-average performance, while negative values for a given company indicate a below-average performance.

Before standardization, we analyzed the correlation matrix (Table 2) for the seven original variables (ROA, ROE, RLC, RLI, DRS, DRC and DRF) presented above.

Table 2. Correlation Matrix.

\begin{tabular}{ccccccccc}
\hline & & ROA & ROE & RLC & RLI & DRS & DRC & DRF \\
\hline \multirow{6}{*}{ Correlation } & ROA & 1.000 & & & & & & \\
& ROE & 0.721 & 1.000 & & & & & \\
& RLC & 0.073 & 0.071 & 1.000 & & & & \\
& RLI & -0.328 & 0.061 & 0.613 & 1.000 & & & \\
& DRS & -0.063 & -0.126 & 0.029 & -0.051 & 1.000 & & \\
& DRC & 0.106 & 0.122 & 0.021 & -0.038 & 0.245 & 1.000 & \\
& DRF & -0.011 & -0.044 & -0.122 & -0.105 & 0.440 & 0.137 & 1.000 \\
\hline \multicolumn{7}{c}{ Source: author's calculation. }
\end{tabular}

The correlation matrix shows the relationship between all the variables considered and also helps us to predict a better representation of them in a smaller number of new variables, called the principal components. Moreover, the strong correlation between the analyzed variables diminished the individual significance of the latter and also highlighted the existence of dissipated information in the connections between the variables. According to Table 2, we can affirm that ROA is correlated with ROE, RLI with RLC, DRS with DRF and DRC with DRS. Therefore, to reduce the size of the initial causal space and to eliminate information redundancy, we will use the principal component analysis (PCA) method. 
One of the most widely used methods of reducing large database indices that has collinearity is the principal component analysis (PCA). This method was invented by Pearson [19] and developed by Hotelling [20]. In addition, PCA has been analyzed over several decades by Cattell, who invented the scree plot [21], Jolliffe [22], and Jolliffe and Cadima [23]. The objectives of PCA are to [24]: extract the most important information from a large set of data; compress the attribute space from a larger number of variables to a smaller number of factors; and select a subset of variables from a larger set, based on which the original variables have the highest correlations with the principal component.

To achieve these objectives, PCA calculates new variables called principal components that are obtained as linear combinations of the original variables. The first main component (PC) extracted recovers the maximum amount of variance from the original variables. The second main component extracted is not correlated with the first main component. Thus, if we calculate the correlation between the first component and the second component, this correlation would be zero. Therefore, the second component represents the maximum amount of variation that remains possible, etc. The values obtained for these new variables are called factor scores. One of the peculiarities of this study is that this method was applied to a panel data set.

In order to choose the number of remaining components, several criteria are used, among which the most important are: Kaiser's criterion, Evrard's criterion and Benzecri's criterion [25]. Kaiser's criterion was proposed by Kaiser in 1960 and consists in choosing the number of axes for which the eigenvalues correspond to a value greater than one. This criterion is one of the most used in PCA.

After the determinants of the financial health of the companies was determined, the next step was to group them into a composite index using the weights of the main components obtained from the analysis of the main components. Therefore, starting from the proportion of the variance recovered by each principal component in the total variation recovered as weights of the factor scores, we determined the non-standardized index. This index measured the financial health of companies from year to year using a linear scale.

We propose that this assessment of the financial health status of the sample companies should be made using a composite index using the principal components analysis specific to the panel data. This method has a number of benefits, such as eliminating correlated features or reducing the amount of size without losing too much information. However, when using this method, we must be careful when selecting the number of main components. We know that this method tries to identify the maximum variation between the functions in a data set. Thus, if we do not correctly select the number of main components, some information may be lost compared to the original list of features. Therefore, the database underlying the analysis was panel data for the period 2011-2018. An objective of this study was to determine the key factors in evaluating the financial health of the test companies using the PCA method for the panel data. The empirical results of the analysis in the main components for the panel data are presented in the table below.

Table 3 contains the eigenvalues for the seven principal components. Based on Kaiser' criterion [26], which states that only the components with eigenvalues greater than 1 can be retained, we kept in our analysis only the first three principal components $\left(C_{1}=1.817, C_{2}=1.731\right.$ and $\left.C_{3}=1.478\right)$. Thus, the first three main components fulfilled the independence hypothesis, a fact emphasized as a result of the elimination of the seven initial variables that had collinearity characteristics. Furthermore, we plotted the eigenvalues presented in Table 3 in a simple line plot. This graphical method is the scree test, proposed for the first time by [21]. 
Table 3. Eigenvalues of the principal components and the Kaiser-Meyer-Olkin (KMO) test.

\begin{tabular}{|c|c|c|c|}
\hline $\begin{array}{l}\mathrm{KMO}=0.326 \\
\text { Sig. }=0.000\end{array}$ & & & \\
\hline \multirow{2}{*}{ Component } & \multicolumn{3}{|c|}{ Initial Eigenvalues } \\
\hline & Total & $\%$ of Variance & Cumulative \% \\
\hline 1 & 1.817 & 25.958 & 25.958 \\
\hline 2 & 1.731 & 24.722 & 50.680 \\
\hline 3 & 1.478 & 21.113 & 71.792 \\
\hline 4 & 0.842 & 12.026 & 83.818 \\
\hline 5 & 0.582 & 8.319 & 92.137 \\
\hline 6 & 0.447 & 6.388 & 98.526 \\
\hline 7 & 0.103 & 1.474 & 100.000 \\
\hline
\end{tabular}

Source: author's calculation.

According to Figure 1, we concluded that only the first three components were representative, while the following had values that tended towards zero. Thus, we can argue that the first principal component explained $25.95 \%$ of the information contained in the underlying correlation matrix, the second $24.72 \%$ and the third $21.11 \%$.

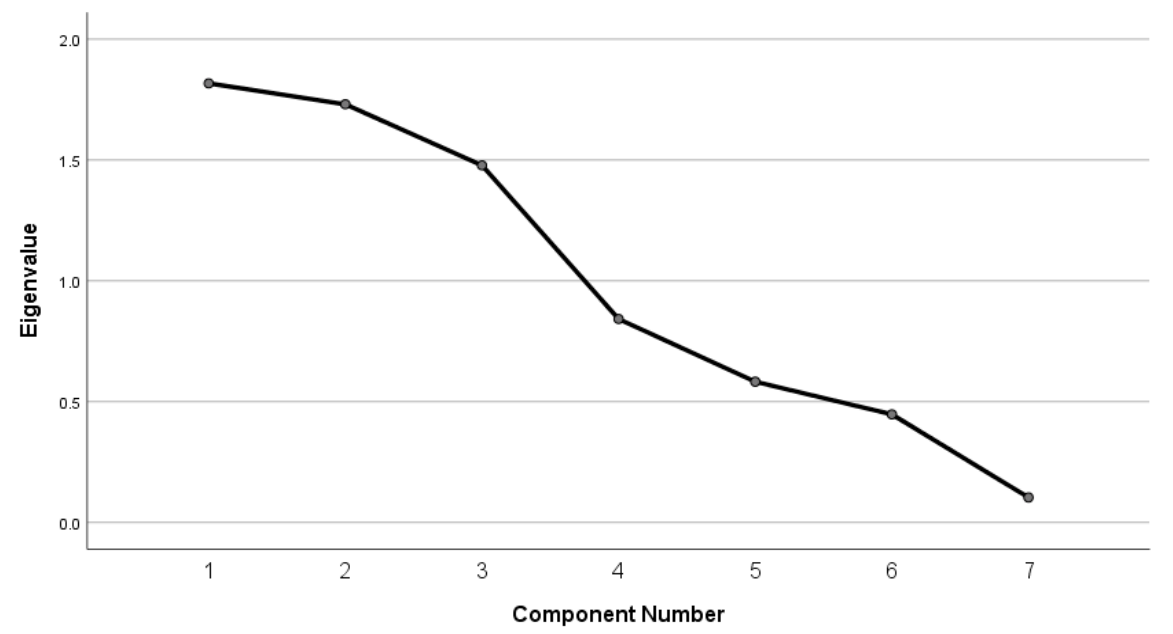

Figure 1. Scree plot of the Eigenvalues after the principal component analysis (PCA) (Source: author's calculation).

After we determined the number of main components kept in the analysis, we continued the study, calculating the matrix of factors for the three principal components resulting from the analysis. The matrix factor is a very important factor, because its elements (also known as factor loading) are the correlation coefficients between the original variables and the principal components.

Within the coordinates system of the three components (Figure 2), powerfully correlated variables were presented and the nature of each principal component was determined. Component 1 was highly correlated to the ROA and ROE indicators and described the efficiency with which a company used its resources to generate profit. These variables described the company's performance from the point of view of the use of the assets owned by the company (ROA) and of the use of the shareholder's capital (ROE). The second identified profitability variables were highly correlated to Component 1 and had a significant influence on the variation of each listed company's calculated score. Depending on the nature of dominant variables, this component exhibited the return rates component related to the financial health of the companies. 


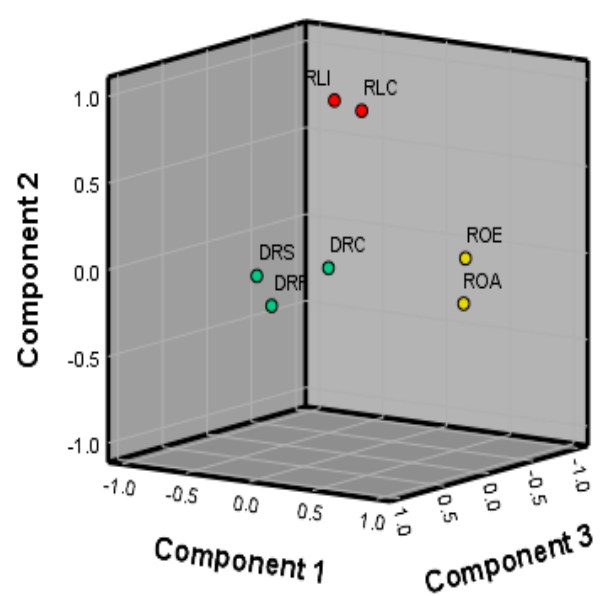

Figure 2. The main principals components based on the financial determining factors.

Component 2 was strongly correlated to the RLC and the RLI and it described the relation between the company's financial health and the liquidity rates. The more these two liquidity rates were higher than 1 , the more financially sound the company was, having the capacity to pay its current debts from its current assets (in case of RLC) or from its most liquid assets (in case of RLI), without resorting to long-term sources. Depending on the nature of the two identified variables, Component 2 was strongly correlated to the RLC and the RLI which had a significant influence on the calculated scores and defined the liquidity rates related to financial health.

Component 3 was highly correlated to the DRS, DRC and the DRF. These variables described the company's financial health, clearly expressing the intensity of the exploitation of the assets of the company. The more intense the companies' assets were exploited, the lower the speed of the rotation was. The three identified variables defined the management rates related to financial health.

Based on the data in Table 4, one can notice that the variation of the return rates was significantly influenced, in a positive manner, by $92.7 \%$ of the ROA indicator variation and by $90.4 \%$ of the ROE variation. The liquidity rates variation was positively influenced by $88.3 \%$ of the RLC variation and by $90.2 \%$ of the variation of the RLI. The variation of the management rates component was significantly influenced, in a positive manner, by $82.8 \%$ of the DRS variation, $74.9 \%$ of the DRF variation and by $56.4 \%$ of the DRC variation. In order to estimate each company's scores, related to each financial component, Table 5 displays the coefficients of linear combinations that define the first three principal components' associated functions.

Table 4. Rotated component matrix.

\begin{tabular}{cccc}
\hline & \multicolumn{2}{c}{ Principal Components of Financial Health } \\
\cline { 2 - 4 } & Return Rates & Liquidity Rates & Management Rates \\
\hline ROA & 0.927 & -0.147 & 0.021 \\
ROE & 0.904 & 0.104 & -0.030 \\
RLC & 0.118 & 0.883 & 0.014 \\
RLI & -0.156 & 0.902 & -0.071 \\
DRS & -0.138 & 0.022 & 0.828 \\
DRC & 0.242 & 0.068 & 0.564 \\
DRF & -0.077 & -0.156 & 0.749 \\
\hline
\end{tabular}

Source: Author's calculation. 
Table 5. The estimations of the score function parameters associated to the principal financial components.

\begin{tabular}{cccc}
\hline & \multicolumn{2}{c}{ Principal Components of Financial Health (Score) } \\
\cline { 2 - 4 } & Return Rates & Liquidity Rates & Management Rates \\
\hline ROA & 0.513 & -0.071 & 0.018 \\
ROE & 0.505 & 0.079 & -0.003 \\
RLC & 0.082 & 0.540 & 0.051 \\
RLI & -0.071 & 0.542 & -0.006 \\
DRS & -0.066 & 0.049 & 0.529 \\
DRC & 0.143 & 0.072 & 0.367 \\
DRF & -0.037 & -0.062 & 0.471 \\
\hline \multicolumn{3}{c}{ Source: Author's calculation. }
\end{tabular}

Based on the data in Table 5, the score functions related to the three principal financial components of 25 listed companies are as follows:

Return rates $=0.513 \times \mathrm{ROA}+0.505 \times \mathrm{ROE}+0.082 \times \mathrm{RLC}-0.071 \times \mathrm{RLI}-0.066 \times \mathrm{DRS}+$ $0.143 \times$ DRC-0.037 $\times$ DRF

Liquidity rates $=-0.071 \times \mathrm{ROA}+0.079 \times \mathrm{ROE}+0.540 \times \mathrm{RLC}+0.542 \times \mathrm{RLI}+0.049 \times \mathrm{DRS}+$ $0.072 \times$ DRC-0.062 $\times$ DRF

Management rates $=0.018 \times \mathrm{ROA}-0.003 \times \mathrm{ROE}+0.05 \times \mathrm{RLC}-0.006 \times \mathrm{RLI}+0.529 \times \mathrm{DRS}+0.367 \times \mathrm{DRC}$ $+0.471 \times \mathrm{DRF}$

After applying the principal components analysis, we identified three principal components which summarized about $72 \%$ of the information generated by the initial variables and thus could identify a model that has the following form:

Z-score $=0.166 \times \mathrm{ROA}+0.208 \times \mathrm{ROE}+0.23 \times \mathrm{RLC}+0.159 \times \mathrm{RLI}+0.148 \times \mathrm{DRS}+0.184 \times \mathrm{DRC}+$ $0.103 \times \mathrm{DRF}$

Or, if we consider the three rates (rates of return, of liquidity and of management, respectively) we have:

Z-score $=0.36 \times$ Return rates $+0.34 \times$ Liquidity rates $+0.29 \times$ Management rates

The representation of the companies in the new space provided by the first three principal components is drawn in Figure 3.

According to the representation of companies in principal components' space and the case scores which led to the identification, we could determine three zones of classification:

- If $\mathrm{Z}$ score $<0$, the companies had a poor financial health, faced with short-term financial difficulties, had an insufficient level of financial performance rates and liquidity rates, an unfavorable gap between the duration of the receivables and the duration of payment of the suppliers and with a medium degree of debt;

- If $Z$ score is between 0 and 0.5 , the companies had a good (stable) financial health, with a sufficient level of liquidity rates, a low degree of indebtedness, but with an unfavorable gap between the duration of receivables and the duration of payment of the suppliers and with a medium degree of debt, although their levels were low;

- If $Z$ score $>0.5$, the companies had a very good financial health, with high liquidity, a very low degree of indebtedness and a very good level of financial performance indicators. 


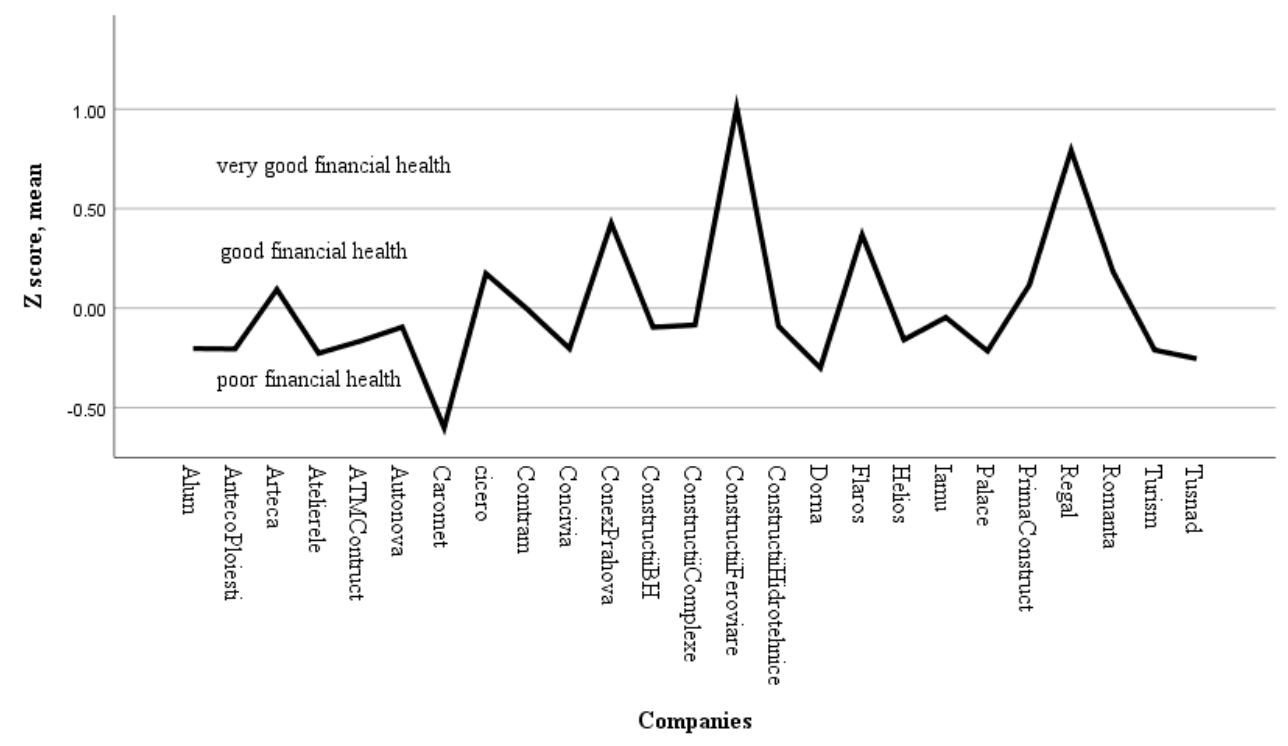

Figure 3. Representation of the companies in principal components' space.

\section{Data Analysis and Discussion of Results}

Our main objective was to develop a score function in order to predict the financial health of the selected SMEs by a combination of seven financial ratios. The range of the $\mathrm{Z}$ score for most SMEs was between -0.5 and 1 . Therefore, after we developed this score function, we proposed three zone of classification based on the Z-score mean. In order to test the financial health of the selected SMEs, we used the one sample $t$-test under the model of the study and the three classifications of $Z$ previously determined by the authors. As we mentioned above, the area determined by the authors for the financially unhealthy SMEs was below 0 while for financially healthy SMEs it was over 0.5. Any Z-score between these two limits placed the SMEs in a stable area with a breakpoint of 0.25 . In this case, the hypotheses are as follows:

Hypotheses 1 (H1). SMEs are considered to be financially healthy.

Hypotheses 2 (H2). SMEs are considered to be financially unhealthy.

Based on the results (Table 6), we can state that above a test value of 0.5, only two SMEs, Constr.Feroviare and Regal, had a positive t-value. Therefore, we can conclude that the mean Z-score lay above 0.5 and that these two SMEs were considered to be financially healthy. Above a test value of 0.25, another three SMEs, Conex Prahova, Floras and Romanta, had a positive and significant $t$-value. Therefore, these three SMEs were considered to be in the financially healthy area. According to the test value $=0$, the results indicated that another three SMEs were financial stable while the other remaining seventeen SMEs were considered to be in a poor financial health area. Although the three SMEs (Arteca, Cicero and Prima Construct) had a negative and significant $t$-value when we used a $t$-test with 0.25 , in the case of the test value $=0$, these three companies had a mean Z-score significantly greater than zero. Thus, we can conclude that the mean Z-score of these three SMEs was significantly lower than 0.25 and higher than 0. Thus, Arteca, Cicero and Prima Construct were financial stable. Therefore, we can conclude that $8 \%$ of the SMEs had a good financial health, $24 \%$ had a stable financial health and $85 \%$ were financially unhealthy. This poor health status was due, in case of the majority of the companies concerned, to the very low financial performance or even the net loss as well as the low liquidity recorded by them from the activity carried out. 
Table 6. $T$-test for the financial health of the small and medium enterprises (SMEs) in Romania.

\begin{tabular}{|c|c|c|c|c|c|c|c|c|c|}
\hline \multirow[b]{2}{*}{ SME } & \multirow[b]{2}{*}{ Mean Z-score } & \multirow[b]{2}{*}{$\mathrm{df}$} & \multicolumn{2}{|c|}{ Test Value $=0.5$} & \multicolumn{2}{|c|}{ Test Value $=0.25$} & \multicolumn{2}{|c|}{ Test Value $=0$} & \multirow[b]{2}{*}{ Financial Health } \\
\hline & & & $t$-Value & $\begin{array}{c}\text { Sig. } \\
\text { (1 Tailed) }\end{array}$ & $t$-Value & $\begin{array}{c}\text { Sig. } \\
\text { (1 Tailed) }\end{array}$ & t-Value & $\begin{array}{c}\text { Sig. } \\
\text { (1 Tailed) }\end{array}$ & \\
\hline Alum & -0.20 & 7 & -6.61 & 0.00 & -4.26 & 0.00 & -1.91 & 0.05 & $\mathrm{PFH}$ \\
\hline AntecoPloiesti & -0.20 & 7 & -14.92 & 0.00 & -9.63 & 0.00 & -4.34 & 0.00 & $\mathrm{PFH}$ \\
\hline Arteca & 0.09 & 7 & -8.54 & 0.00 & -3.28 & 0.01 & 1.99 & 0.04 & SFH \\
\hline Atelierele & -0.23 & 7 & -10.14 & 0.00 & -6.65 & 0.00 & -3.16 & 0.01 & $\mathrm{PFH}$ \\
\hline ATMContruct & -0.17 & 7 & -42.84 & 0.00 & -26.75 & 0.00 & -10.65 & 0.00 & $\mathrm{PFH}$ \\
\hline Autonova & -0.09 & 7 & -15.27 & 0.00 & -8.85 & 0.00 & -2.44 & 0.02 & PFH \\
\hline Caromet & -0.60 & 7 & -2.13 & 0.04 & -1.65 & 0.07 & -1.16 & 0.02 & PFH \\
\hline Cicero & 0.17 & 7 & -4.90 & 0.00 & -1.14 & 0.15 & 2.61 & 0.03 & SFH \\
\hline Comtram & -0.01 & 7 & -12.34 & 0.00 & -6.26 & 0.00 & -0.18 & 0.43 & PFH \\
\hline Concivia & -0.20 & 7 & -15.46 & 0.00 & -9.96 & 0.00 & -4.46 & 0.00 & PFH \\
\hline ConexPrahova & 0.43 & 7 & -0.34 & 0.37 & 0.826 & 0.06 & & & SFH->GFH \\
\hline ConstructiiBH & -0.10 & 7 & -127.76 & 0.00 & -74.14 & 0.00 & -20.52 & 0.00 & $\mathrm{PFH}$ \\
\hline Constr.Complexe & -0.08 & 7 & -15.02 & 0.00 & -8.60 & 0.00 & -2.17 & 0.03 & $\mathrm{PFH}$ \\
\hline Constr.Feroviare & 1.01 & 7 & 1.13 & 0.15 & & & & & GFH \\
\hline Constr.Hidroteh & -0.09 & 7 & -22.91 & 0.00 & -13.23 & 0.00 & -3.54 & 0.01 & $\mathrm{PFH}$ \\
\hline Dorna & -0.30 & 7 & -134.85 & 0.00 & -92.74 & 0.00 & -50.63 & 0.00 & $\mathrm{PFH}$ \\
\hline Flaros & 0.37 & 7 & -1.02 & 0.17 & 0.917 & 0.09 & & & SFH->GFH \\
\hline Helios & -0.16 & 7 & -167.60 & 0.00 & -104.01 & 0.00 & -40.43 & 0.00 & $\mathrm{PFH}$ \\
\hline Iamu & -0.05 & 7 & -23.85 & 0.00 & -12.93 & 0.00 & -2.02 & 0.04 & $\mathrm{PFH}$ \\
\hline Palace & -0.22 & 7 & -62.91 & 0.00 & -40.93 & 0.00 & -18.95 & 0.00 & PFH \\
\hline PrimaConstruct & 0.12 & 7 & -5.38 & 0.00 & -1.87 & 0.06 & 1.64 & 0.10 & SFH \\
\hline Regal & 0.79 & 7 & 1.37 & 0.11 & & & & & GFH \\
\hline Romanta & 0.18 & 7 & -0.82 & 0.22 & 0.171 & 0.06 & & & SFH->GFH \\
\hline Turism & -0.21 & 7 & -6.46 & 0.00 & -4.19 & 0.00 & -1.92 & 0.05 & PFH \\
\hline Tusnad & -0.25 & 7 & -18.37 & 0.00 & -12.28 & 0.00 & -6.18 & 0.00 & PFH \\
\hline
\end{tabular}

Note: GFH—good financial health, SFH—Stable financial health, PFH—poor financial health; Source: Author's calculation.

Table 7 shows the regression result models with solvency as the dependent variable and having return rates, liquidity rates and management rates as the independent variables. In the second part of the table, we study the relation between the financial health index (Z-score) and the financial leverage.

In the first model (1), the three variables that measured the rates of return, liquidity, and of management, respectively, of the companies, were statistically significant at 0.10 level. At the level of the 25 companies analyzed, all three rates were positively correlated with solvency. Estimations of the first model (1) showed a positive and statistically significant relation between solvency and the three rates determined using the analysis of the principal components. Thus, an increase of $1 \%$ of the return rates would increase the degree of solvency by approximately $9 \%$, while an increase of $1 \%$ of management rate would increase the degree of solvency by approximately $10 \%$. The highest influence on the solvency was the liquidity rate, which led to an increase of solvency by $56 \%$. In terms of the intensity of the correlation between solvency and the three rates determined using the PCA, we found an R-squared equal to 0.35 . This result showed that these independent variables explained approximately $35 \%$ of the dependent variable variance, i.e., solvency.

If we corelate the financial health index determined with the PCA method with the degree of solvency, the results also show a positive and statistically significant relation between this index and solvency (see Figure 4). According to the scatter plot (Figure 4), we can say that among the companies with the best financial health performance and a high solvency rate are Constructii Feroviare, Flaros, Regal and Conex Prahova. 
Table 7. Regression analysis with the panel data.

\begin{tabular}{ccc}
\hline & \multicolumn{2}{c}{ Dependent Variable } \\
\cline { 2 - 3 } & Solvency Rate & Financial Health Index (Z-score) \\
\hline Independent variable & $(1)$ & $(2)$ \\
\hline Return rates & $0.098^{*}$ & \\
\hline Liquidity rates & $(0.09)$ & \\
\hline Management rates & $0.569^{* * *}$ & \\
\hline Financial leverage & $(0.00)$ & $-0.1505^{* * *}$ \\
\hline R-squared & $(0.02)$ & $(0.00)$ \\
\hline F-statistic & & 0.067 \\
\hline Prob (F-Statistic) & 0.350 & 14.32 \\
\hline Observation & 200 & 0.00 \\
\hline
\end{tabular}

$* * *, * *$ denotes rejection of the null hypothesis at the 0.10 level, 0.05 level, respectively 0.01 level; Source: Author's calculation.

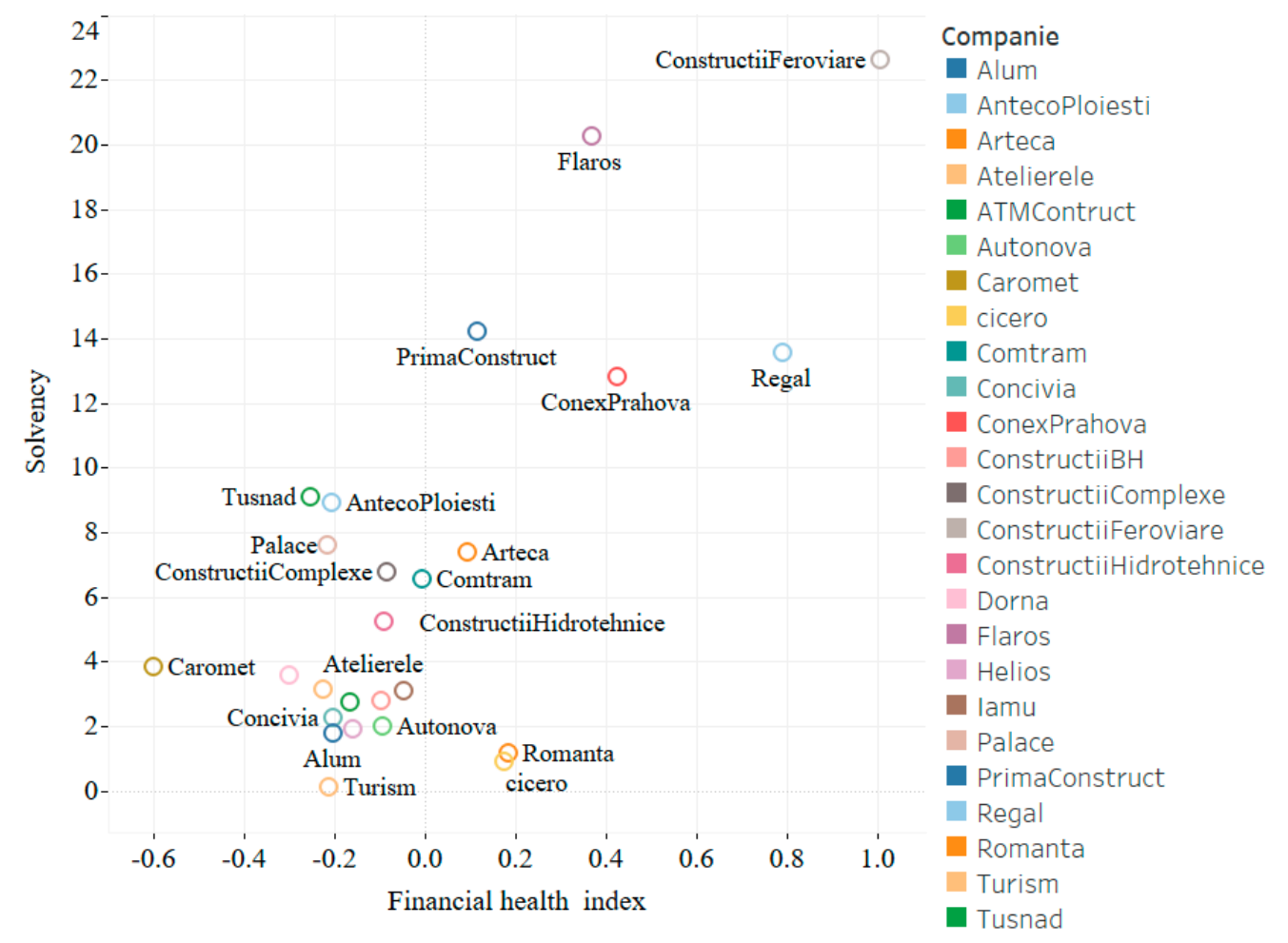

Figure 4. The relationship between the solvency rate and the financial health index for the 25 listed companies. Source: Author's calculation.

The second part of Table 7 presents the regression results for the model that had as the dependent variable the financial health index. In model (2) we correlated the financial health index with the financial leverage. The estimation showed a negative and statistically significant relation between these two indicators: an increase of $1 \%$ of the financial leverage would decrease the financial health index by $15 \%$, since the relation between the equity and the financial leverage was an antagonistic one. In order to obtain a higher financial health, the company should aim for an optimal capital 
structure, obtained by the best mix of debt and equity financing that in the same time can maximize the company's market value while minimalizing its cost of capital.

In order to predict the future value of the solvency rate, we used model (1). Given that this model had all the coefficients statistically significant and the residuals autocorrelated, we could verify the prediction ability of this estimated model for the future value of the solvency rate. Considering that in order to determine the financial health of the companies, we proposed three classification intervals, for a more accessible interpretation, and we divided the variables according to the three intervals (0-poor, 1-stable and 2-good). We compared the predicted value of the solvency rate with the real value. The results are presented in Table 8.

Table 8. Prediction ability of the model (1).

\begin{tabular}{ccccccc}
\hline & & \multicolumn{5}{c}{ Prediction } \\
\hline & & & Poor & Stable & Good & Total \\
\hline \multirow{3}{*}{ (Real) RSG } & \multirow{2}{*}{ poor } & Count & 130 & 6 & 1 & 137 \\
\cline { 3 - 7 } & & $\%$ & $94.9 \%$ & $4.4 \%$ & $0.7 \%$ & $100 \%$ \\
\cline { 3 - 7 } & \multirow{2}{*}{ stable } & Count & 22 & 18 & 5 & 45 \\
\cline { 3 - 7 } & & $\%$ & $48.9 \%$ & $40 \%$ & $11.1 \%$ & $100 \%$ \\
\cline { 3 - 7 } & \multirow{2}{*}{ good } & Count & 0 & 5 & 13 & 18 \\
\cline { 3 - 7 } & & $\%$ & $0.0 \%$ & $27.8 \%$ & $72.2 \%$ & $100 \%$ \\
\hline & & Count & 152 & 29 & 19 & 200 \\
\cline { 3 - 7 } & & $\%$ & $76.0 \%$ & $14.5 \%$ & $9.5 \%$ & $100 \%$ \\
\hline
\end{tabular}

$85.5 \%$ of the initially grouped cases were correctly classified

Source: Author's calculation.

According to the results we claimed that the former model of the solvency rate identified correctly $94.9 \%$ of the SMEs with poor financial health, $40 \%$ of the SMEs with stable financial health and $72.2 \%$ of the SMEs with good financial health. The total prediction ability of the model was $85.5 \%$, which according to Klepác $`$ and Hampel [27] is good (0.75 and 0.92).

\section{Conclusions and Limits}

This paper aimed to develop a scoring function taking into account seven financial and economic indicators for the activity of the companies. We grouped the companies into three categories according to the value of the financial composite index: companies with poor financial health $(z<0)$, companies with good financial health $(0 \leq z \leq 0.5)$ and companies with very good financial health $(z>0.5)$.

The three components of the financial health index contributed directly and positively to it, the largest contribution of 0.36 being from the return rates. Moreover, the results showed a positive and statistically significant relation between solvency and the three rates (of return, of liquidity and of management, respectively) determined using the analysis of the principal components, the biggest influence coming from the liquidity rates.

Analyzing the significant negative correlation between the financial leverage and the financial health index of the companies, we can say that the increase in the degree of indebtedness determines the deterioration of its financial health.

This study was useful for diagnosing the financial health of small and medium-sized companies. A limitation of this model was that it may not have yielded conclusive results for large companies.

Due to the fact that this article was financed through the Interreg V-A Romania-Hungary Programme, we were limited to selecting only SMEs from Romania, who are also the beneficiaries of the results of the project we implemented. 
Through this research we wanted to determine a score function that studied the financial performance of SMEs in Romania. The lack of data from the analyzed period, for a series of indicators, led to a sample of only 25 companies. Future research could be expanded by selecting variables for which data are available so that we can empirically analyze the financial health of companies and test the models of financial health prediction for several SMEs. Therefore, by taking a larger sample, it will lead to much more robust models.

Author Contributions: Conceptualization: C.D.S.-P. and R.S.; data curation: L.D. and C.C.B.; methodology and research design: C.D.S.-P. and R.S.; formal analysis, C.D.S.-P. and R.S.; investigation: L.D. and C.C.B.; writing-original draft preparation: R.S. and C.C.B.; writing-review and editing: C.D.S.-P. and L.D.; validation: R.S. and L.D.; visualization: C.D.S.-P., R.S. and C.C.B.; supervision: C.D.S.-P. All authors have read and agreed to the published version of the manuscript.

Funding: This research was funded within the project, "Institutional cooperation in research activities for specialists, training and usage of computational intelligence for fundamenting companies' financial decisions", eMS Code: ROHU-217, grant number 11056/23.01.2019. The project, "Institutional cooperation in research activities for specialists, training and usage of computational intelligence for fundamenting companies' financial decisions", is implemented under the, Interreg V-A Romania-Hungary Programme and is financed by the European Union through the European Regional Development Fund, Romania and Hungary. Partnership for a better future: www.interreg-rohu.eu
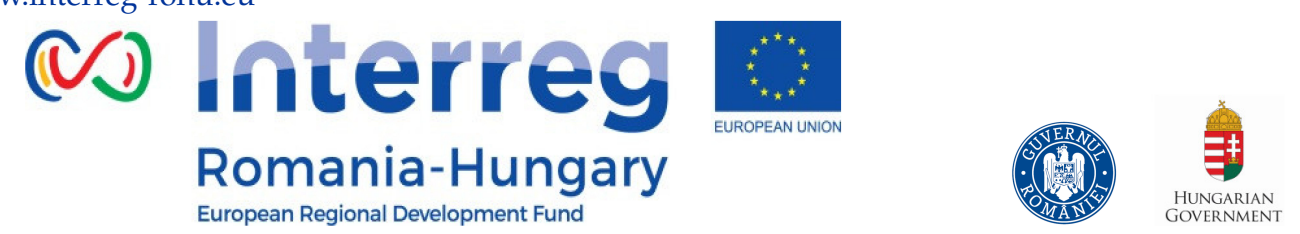

Acknowledgments: The content of this material does not necessarily represent the official position of the European Union.

Conflicts of Interest: The authors declare no conflict of interest. The funders had no role in the design of the study; in the collection, analyses, or interpretation of data; in the writing of the manuscript, or in the decision to publish the results.

\section{References}

1. European Commission Annual Report on European SMEs 2018/2019. Available online: https://ec.europa.eu/ growth/smes/business-friendly-environment/performance-review_en (accessed on 15 February 2020).

2. Zabolotnyy, S.; Wasilewski, M. The Concept of Financial Sustainability Measurement: A Case of Food Companies from Northern Europe. Sustainability 2019, 11, 5139. [CrossRef]

3. Sannikova, I.N. The Company's Financial Health Is The Basis Of Sustainable Development. Eur. Proc. C. Behav. Sci. EPSBS 2019. [CrossRef]

4. Diana, S.C.; Ioan, B.M.; Bradea, I.A. Influence of the Capital Structure on the Companies Performance. Study on the Energy Sector Companies Listed on BSE, lucrare prezentata în cadrul celei de a 12th International Conference on European Integration-New Challenges-EINCO 2016, Oradea, 26-28 May 2016, publicata în Analele Universităţii din Oradea, seria Ştiinţe Economice, Tom XXV 2016, revista cotata CNCSIS B+, pag. 1040-1048, 1st issue july 2016, ISSN - 122569 (în format tipărit), ISSN-1582-5450 (în format electronic), indexată în BDI RePeC, EBSCO, DOAJ. Available online: http://anale.steconomiceuoradea.ro/volume/2016/ AUOES-1-2016.pdf (accessed on 29 January 2020).

5. Nyabwanga, R.N.; Ojera, P.; Simeyo, O.; Nyakundi, F. An Empirical Analysis of the Liquidity, Solvency and Financial Health of Small and Medium Sized Enterprises in Kisii Municipality, Kenya. Eur. J. Bus. Manag. 2013, 5, 1-15, ISSN 2222-1905 (Paper) ISSN 2222-2839 (Online).

6. Maciková, L.; Smorada, M.; Dorčák, P.; Beug, B.; Markovič, P. Financial Aspects of Sustainability: An Evidence from Slovak Companies. Sustainability 2018, 10, 2274. [CrossRef]

7. Salawu, R.O. The effect of capital structure on profitability: An empirical analysis of listed firms in Nigeria. Int. J. Bus. Finance Res. 2009, 3, 121-127, ISSN 2157-0698.

8. Lassala, C.; Apetrei, A.; Sapena, J. Sustainability Matter and Financial Performance of Companies. Sustainability 2017, 9, 1498. [CrossRef] 
9. Kočišová, K.; Kovacova, M. Discriminant Analysis as a Tool for Forecasting Company's Financial Health. Procedia Soc. Behav. Sci. 2014, 110, 1148-1157. [CrossRef]

10. Hur-Yagba, A.A.; Okeji, I.F.; Ayuba, B. Analyzing Financial Health of Manufacturing Companies in Nigeria Using Multiple Discriminate Analysis. Int. J. Manag. Stud. Res. (IJMSR) 2015, 3, 72-81, ISSN 2349-0330 (Print) \& ISSN 2349-0349 (Online).

11. Paun, D. Sustainability and Financial Performance of Companies in the Energy Sector in Romania. Sustainability 2017, 9, 1722. [CrossRef]

12. Čámská, D.; Scholleová, H. Financial Health of Companies Supported by European Funds. Econ. Manag. 2012, 17, 17. [CrossRef]

13. Wakar, B.A.; Poznyak, D. Cluster Sampling. Sage Encycl. Educ. Res. Meas. Eval. 2018. [CrossRef]

14. Pfeffermann, D.; Rao, C.R. Sample Surveys: Design, Methods and Application, Handbook of Statistics, 1st ed.; Elsevier: Amsterdam, The Netherlands, 2009; Volume 29A, ISBN 9780444531247.

15. Available online: www.bvb.ro (accessed on 8 January 2020).

16. Şamiloğlu, F.; Öztop, A.O.; Kahraman, Y.E. The Determinants of Firm Financial Performance: Evidence From Istanbul Stock Exchange (BIST). IOSR J. Econ. Finance (IOSR-JEF) 2017, 8, 62-67, e-ISSN: 2321-5933, p-ISSN: 2321-5925.

17. Freudenberg, M. Composite Indicators of Country Performance; Organisation for Economic Co-Operation and Development (OECD): Paris, France, 2003.

18. OECD; Union, E. Joint Research Centre-European Commission Handbook on Constructing Composite Indicators: Methodology and User Guide. In Handbook on Constructing Composite Indicators: Methodology and User Guide; OECD: Paris, France, 2008.

19. Pearson, K. LIII. On lines and planes of closest fit to systems of points in space. Lond. Edinb. Dublin Philos. Mag. J. Sci. 1901, 2, 559-572. [CrossRef]

20. Hotelling, H. Analysis of a complex of statistical variables into principal components. J. Educ. Psychol. 1933, 24, 417-441. [CrossRef]

21. Cattell, R.B. The Scree Test For The Number Of Factors. Multivar. Behav. Res. 1966, 1, 245-276. [CrossRef] [PubMed]

22. Richards, L.E.; Jolliffe, I.T. Principal Component Analysis. J. Mark. Res. 1988, 25, 410. [CrossRef]

23. Jolliffe, I.T.; Cadima, J. Principal component analysis: A review and recent developments. Philos. Trans. R. Soc. A Math. Phys. Eng. Sci. 2016, 374, 20150202. [CrossRef] [PubMed]

24. Chandra, P.L.; al Suman, S.A.; Nahid, S. Methodological Analysis of Principal Component Analysis (PCA) Method. IJCEM Int. J. Comput. Eng. Manag. 2013, 16, 32-38, ISSN (Online) 2230-7893.

25. Saporta, G.; Stefanescu, M.V. Analiza Datelor şi Informatică; Economica Press: Bucharest, Romania, 1996.

26. Kaiser, H.F. The Application of Electronic Computers to Factor Analysis. Educ. Psychol. Meas. 1960, 20, 141-151. [CrossRef]

27. Klepáč, V.; Hampel, D. Prediction of Bankruptcy with SVM Classifiers Among Retail Business Companies in EU. Acta Univ. Agric. Silvic. Mendel. Brun. 2016, 64, 627-634. [CrossRef] 